\title{
THE PHOSPHOLIPID COMPOSITION OF HUMAN SPERMATOZOA AND SEMINAL PLASMA
}

\author{
A. POULOS AND I. G. WHITE \\ Department of Veterinary Physiology, University of Sydney, Sydney, Australia
}

(Received 10th October 1972)

\begin{abstract}
Summary. The phospholipid composition of human spermatozoa and seminal plasma was examined by quantitative two-dimensional thinlayer chromatography, followed by phosphorus analysis. Sperm phospholipid comprised $28 \cdot 8 \%$ phosphatidyl choline, $21 \cdot 6 \%$ phosphatidyl ethanolamine, $21.4 \%$ sphingomyelin, $9.4 \%$ ethanolamine plasmalogen, $4.7 \%$ phosphatidyl serine, $2.7 \%$ choline plasmalogen, $1.9 \%$ phosphatidyl inositol and $1.6 \%$ cardiolipin.

Seminal plasma phospholipids comprised $44.0 \%$ sphingomyelin, $12.3 \%$ ethanolamine plasmalogen, $11.2 \%$ phosphatidyl serine, $8.5 \%$ phosphatidyl ethanolamine, $7 \cdot 8 \%$ phosphatidyl choline, $0.8 \%$ choline plasmalogen, $0.8 \%$ cardiolipin and $1.7 \%$ phosphatidyl inositol.

Prolonged aerobic incubation of human spermatozoa in the presence or absence of glucose produced no significant alteration either in the amount of phospholipid phosphorus extracted or in the phospholipid composition of this extracted material.
\end{abstract}

\section{INTRODUCTION}

Although a considerable amount of information has been amassed on the phospholipid composition of the spermatozoa of ram (Hartree \& Mann, 1961; Scott, Voglmayr \& Setchell, 1967), bull (Pursel \& Graham, 1967) and boar (Grogan, Mayer \& Sikes, 1966; Johnson, Gerrits \& Young, 1969), little work has been carried out on the phospholipid composition of human spermatozoa. This may be at least partially due to the low sperm concentration of human semen which necessitates the use of large numbers of ejaculates before sufficient lipid material can be isolated and analysed. Minassian \& Terner (1966) showed the presence of ethanolamine and choline phospholipids, and plasmalogen in human spermatozoa, although whether the latter was present in the choline or ethanolamine form was not determined. The only other phospholipid mentioned as being present in their extracts was polyglycerophosphatide.

The present investigation was undertaken to determine the phospholipid composition of human spermatozoa and seminal plasma, and to compare the pattern with similar analyses carried out on the semen of other mammalian species. 


\section{MATERIALS AND METHODS}

\section{Semen collection and extraction}

Semen was obtained by massage from normal subjects. Only semen of good motility was used and in most cases was processed within 90 min of collection. The semen, usually three or four pooled ejaculates, was diluted with 3 vols of calcium-free Krebs-Ringer phosphate (Umbreit, Burris \& Stauffer, 1959), pH $7 \cdot 3$, and then centrifuged at $500 \mathrm{~g}$ for $20 \mathrm{~min}$ at room temperature $\left(20\right.$ to $\left.25^{\circ} \mathrm{C}\right)$. The pellet was resuspended in $10 \mathrm{ml}$ Krebs-Ringer phosphate and the sperm concentration was determined by taking an average of three haemocytometer counts.

Both the sperm suspension and the diluted seminal plasma supernatant were extracted according to the method of Bligh \& Dyer (1959). Initially, the extracts were allowed to stand in solvent under nitrogen overnight at $4^{\circ} \mathrm{C}$ since it was felt that a more complete extraction would be achieved under these circumstances. There was little difference, however, between the amounts of phospholipid extracted under these conditions or during a 3-hr solvent exposure, and thus the shorter procedure was used more frequently. The extracts were filtered through sintered glass funnels, the latter having been packed with Hyflo-Supercel previously washed by refluxing in methanol for $2 \mathrm{hr}$. During the washing procedure, emulsions formed, especially during extraction of seminal plasma, but these were mostly cleared by warming and, in some instances, by centrifugation. The lower phase resulting from the extraction procedure was evaporated to dryness in a rotary evaporator at $40^{\circ} \mathrm{C}$ and the residue dried repeatedly (three times) from chloroform-methanol $(2: 1, \mathrm{v} / \mathrm{v})$ solutions containing $4 \%(\mathrm{v} / \mathrm{v})$ of water. This procedure was used to remove any proteolipids which may have been present (Ansell \& Hawthorne, 1964) and was largely successful since amounts of proteolipid running at the origin on the two-dimensional chromatograms rarely exceeded $2 \%$ of the total recovered phospholipid phosphorus. The final washed, water-free residue was dissolved in chloroform-methanol $(4: 1, \mathrm{v} / \mathrm{v})$ and stored under nitrogen at $-10^{\circ} \mathrm{C}$ until ready for analysis.

\section{Materials}

Most lipid standards were purchased from Sigma, St Louis, U.S.A. Phosphatidyl inositol was obtained from Applied Science Labs, U.S.A. Cetyl vinyl ether was obtained from Pfaltz Bauer, Flushing, U.S.A.

\section{Methods of analysis}

Phosphorus was assayed as described by Owens \& Hughes (1970), fructose analysis was carried out as described by Klotzsch \& Bergmeyer (1963) and $\alpha \beta$-unsaturated ether analysis was performed by the method of Gottfried \& Rapport (1962) using cetyl vinyl ether as a standard.

Two-dimensional thin-layer chromatographic analysis of phospholipid mixtures was performed in the following manner. The phospholipid mixture $(0.30$ to $0.35 \mu \mathrm{g}$ atoms of phospholipid phosphorus) was applied to the lower 
left-hand edge of a $20 \times 20 \mathrm{~cm}$ plate of silica gel $\mathrm{H}$ (thickness $250 \mu \mathrm{m}$ ) previously washed with chloroform-methanol-water $(60: 35: 8$, by vol.). After development in chloroform-methanol-concentrated ammonia $(70: 30: 5$, by vol.), excess ammonia was removed by blowing a stream of cold air for $1 \mathrm{~min}$ over the plate, and placing in a vacuum oven at $30^{\circ} \mathrm{C}$ for $1 \mathrm{hr}$. Removal of excess ammonia was an important part of the procedure since failure to do so led to the formation of ammonium chloride on the plate which interfered with the second dimensional run. Plasmalogen alk-1-enyl ether linkages were then cleaved by exposing the plate to concentrated hydrochloric acid vapours $(32 \%, \mathrm{w} / \mathrm{w})$ as described by Horrocks (1968). Excess acid vapours were removed by blowing cold air over the plate for $1 \mathrm{~min}$, and the plate was reactivated in a vacuum oven at $30^{\circ} \mathrm{C}$ over $\mathrm{P}_{2} \mathrm{O}_{5}$ or silica gel. Phospholipid zones, located by spraying the plate with $18 \mathrm{~N}$-sulphuric acid and charring in an oven at $180^{\circ} \mathrm{C}$ for $20 \mathrm{~min}$, were scraped from the plate and assayed for inorganic phosphorus after digestion with $70 \%(\mathrm{w} / \mathrm{v})$ perchloric acid. The average yield of phosphorus recovered from the plates was $92 \%$. The results for plasmalogen determined by Horrocks' procedure were in good agreement with those determined by $\alpha \beta$-unsaturated ether analysis which involves an assay of the plasmalogen unsaturated ether linkage.

\section{Proof of identity of spermatozoan and seminal plasma lipids}

The proof of identity of the various phospholipids was based initially on a comparison of their mobilities on thin-layer chromatography with phospholipid standards in three separate solvent systems. Choline-containing lipids were detected with the Dragendorff reagent and serine and ethanolamine phospholipids with ninhydrin reagent. In addition, lipid extracts were hydrolysed according to the procedure of Dawson (1960) and Dawson, Hemington \& Davenport (1962) and the water-soluble phosphate esters derived from the various phospholipids were chromatographed on Whatman No. 1 paper in conjunction with standards. Other lipid extracts (2 to $4 \mu \mathrm{g}$ atoms of lipid phosphorus) were hydrolysed with $6 \mathrm{~N}-\mathrm{HCl}$ at $105^{\circ} \mathrm{C}$ for $3 \mathrm{hr}$, the lipid was removed by washing with petroleum ether, and the water-soluble material, after repeated evaporation from an aqueous solution to remove $\mathrm{HCl}$, was chromatographed as described by Dittmer \& Wells (1969). Choline was detected using the Dragendorff reagent and serine and ethanolamine with ninhydrin. The presence of sphingomyelin was confirmed by hydrolysis of the lipid extracts with hydrochloric acid in methanol (Sweeley \& Gaver, 1965) and detection of sphingosine in the hydrolysate by thin-layer chromatography on silica gel $G$ plates (made with $0.01 \mathrm{M}$-sodium carbonate in chloroformmethanol-water (100:42:5, by vol.).

\section{RESULTS}

Table 1 shows the amounts of phospholipid phosphorus extracted from human spermatozoa and seminal plasma and the composition of individual phospholipid components. There was considerable variation in the amounts of phospholipid extracted from the seminal plasma and spermatozoa of different 
ejaculates. This variation did not seem to be related to the extraction procedure since it was found that, while the phospholipid extracted from spermatozoa of different animals within the same species (ram, boar, bull) varied considerably in amount, the phospholipid content of duplicate extracts of spermatozoa obtained from the same animal generally agreed to within $10 \%$ (Poulos, Darin \& White, 1972). The phospholipid concentrations and compositions of freshly ejaculated semen, and semen incubated aerobically at 20 to $25^{\circ} \mathrm{C}$ for $100 \mathrm{~min}$ were compared. There was little alteration in either the concentration or the composition of semen phospholipids which indicated that the variation in amounts of phospholipid extracted from the spermatozoa and seminal plasma was not due to degradation of phospholipid components by semen phospholipases.

Table 1. Phospholipids of human spermatozoa and seminal plasma

\begin{tabular}{|c|c|c|c|c|}
\hline \multirow[b]{2}{*}{ Lipid zone } & \multicolumn{2}{|c|}{ Spermatozoa } & \multicolumn{2}{|c|}{ Seminal plasma } \\
\hline & $\begin{array}{c}\mu g \text { atoms of } \\
P / 10^{9} \\
\text { spermatozoa }\end{array}$ & $\begin{array}{c}\% \text { lipid } P \text { in } \\
\text { total } \\
\text { extracted } \\
\text { phospholipid } \\
P\end{array}$ & $\begin{array}{c}\mu g \text { atoms lipid } \\
P / 100 \mathrm{ml} \\
\text { seminal plasma }\end{array}$ & $\begin{array}{c}\% \text { of lipid } P \\
\text { in total } \\
\text { extracted } \\
\text { phospholipid } \\
P\end{array}$ \\
\hline $\begin{array}{l}\text { Sphingomyelin } \\
\text { Phosphatidyl choline* } \\
\text { Choline plasmalogen } \\
\text { Phosphatidyl serine } \\
\text { Ethanolamine plasmalogen } \\
\text { Phosphatidyl ethanolamine } \\
\text { Cardiolipin } \\
\text { Phosphatidyl inositol } \\
\text { Miscellaneous lipids } \\
\text { Total lipid P extracted }\end{array}$ & $\begin{array}{l}0.422 \pm 0.024 \\
0.568 \pm 0.016 \\
0.053 \pm 0.008 \\
0.093 \pm 0.008 \\
0.185 \pm 0.020 \\
0.426 \pm 0.026 \\
0.032 \pm 0.008 \\
0.337 \pm 0.025 \\
0.156 \pm 0.038 \\
1.973 \pm 0.11\end{array}$ & $\begin{array}{r}21.4 \\
28.8 \\
2.7 \\
4.7 \\
9.4 \\
21.6 \\
1.6 \\
1.9 \\
7.9\end{array}$ & $\begin{array}{l}17 \cdot 16 \pm 0.62 \\
3.04 \pm 0.27 \\
0.31 \pm 0.08 \\
4.37 \pm 0.27 \\
4.80 \pm 0.31 \\
3.32 \pm 0.23 \\
0.31 \pm 0.19 \\
0.66 \pm 0.19 \\
5.03 \pm 0.89 \\
39.0 \pm 2.5\end{array}$ & $\begin{array}{r}44 \cdot 0 \\
7 \cdot 8 \\
0 \cdot 8 \\
11 \cdot 2 \\
12 \cdot 3 \\
8 \cdot 5 \\
0 \cdot 8 \\
1 \cdot 7 \\
12 \cdot 9\end{array}$ \\
\hline
\end{tabular}

* The phosphatidyl choline area may include 1-alkyl 2-acyl glycero-3-phosphorylcholine.

$\uparrow$ The phosphatidyl ethanolamine area may include 1-alkyl 2-acyl glycero-3-phosphoryl ethanolamine. Mean values $\pm S$.E. are given for six sperm. and five seminal plasma samples.

Several phospholipid species were detected in both sets of extracts (Table 1). The most outstanding differences between the percentage phospholipid compositions of human spermatozoa and seminal plasma lie in the high concentrations of phosphatidyl choline and phosphatidyl ethanolamine in spermatozoa, and in the high concentrations of phosphatidyl serine and sphingomyelin in seminal plasma. The latter is probably not the sole component of what is described as the sphingomyelin zone since there appeared to be two other components, one of which reacted with ninhydrin, while the other substance migrated in the same region of the thin-layer plates as an unknown phospholipid found in most other mammalian spermatozoa (Poulos et al., 1972). These two components are included in the sphingomyelin zone since in most instances they were not separated sufficiently from the major sphingomyelin area to permit accurate quantification. On occasions when a partial separation was achieved, at least $80 \%$ of the total phosphorus present in the area was localized in the sphingomyelin zone. 
When the sperm and seminal plasma extracts were chromatographed (Owens, 1966) in one dimension in the acid solvent, chloroform-methanolwater-acetic acid (65:43:3:1, by vol.), and a phosphorus analysis was carried out on the various zones, the sphingomyelin area was found to contain less phosphorus than the two-dimensional sphingomyelin zone, suggesting that the use of acid solvent systems facilitates the separation of sphingomyelin from the other two components. Both spermatozoa and seminal plasma contained small amounts of other substances, although the percentage of the total phosphorus contained in any one of these substances was rarely higher than 2. All of these substances, together with small amounts of phosphorus-containing material (generally $<4 \%$ ) remaining at the origin of the second dimension development, are listed in Table 1 as 'miscellaneous lipids'. At least some of the latter material may be breakdown products of phospholipids due either to oxidation or to acid action.

\section{Extraction of phospholipids from human spermatozoa after aerobic incubation}

In an enquiry into the utilization of endogenous phospholipids as an energy source by human spermatozoa, three ejaculates (total volume, $7.5 \mathrm{ml}$ ) were centrifuged at $500 \mathrm{~g}$ for $30 \mathrm{~min}$ at room temperature $\left(20\right.$ to $\left.25^{\circ} \mathrm{C}\right)$. The seminal plasma was removed and the spermatozoa $\left(1 \cdot 125 \times 10^{9}\right.$ cells $)$ were resuspended in $10 \mathrm{ml}$ of calcium-free Krebs-Ringer phosphate buffer, $\mathrm{pH} 7 \cdot 3$, containing $1 \mathrm{mg}$ penicillin/ml and $1 \mathrm{mg}$ streptomycin $/ \mathrm{ml}$. Aliquots $(3-\mathrm{ml})$ were extracted (a) immediately, (b) after aerobic incubation at $37^{\circ} \mathrm{C}$ for $6 \mathrm{hr}$, and (c) after similar incubation in the presence of $3 \mathrm{mg}$ glucose $/ \mathrm{ml}$. The suspensions were shaken at intervals during incubation. The amount of contaminating seminal plasma fructose, less than $0.04 \mathrm{mg} / \mathrm{ml}$ was considered insufficient to keep the spermatozoa motile during extended incubation. Under these conditions, it was felt that the phospholipid content of the spermatozoa may have been reduced. However, despite the fact that the spermatozoa retained some of their motility after the incubation period, an analysis of the total phospholipid extracted from the spermatozoa revealed that the amounts of lipid phosphorus extracted per $10^{9}$ cells from non-incubated cells $(1.97 \mu \mathrm{g}$ atoms) showed little change after incubation in the presence or absence of glucose $(2.08$ and 2.04 $\mu \mathrm{g}$ atoms lipid phosphorus, respectively). This result was confirmed on two further occasions. Analysis of the percentage composition of phospholipid components of the spermatozoa demonstrated little change in composition, and two possible breakdown products, lysolecithin and lysophosphatidyl ethanolamine, did not change in concentration.

\section{DISGUSSION}

The amount of phospholipid extracted from human spermatozoa is similar to the amount extracted from the ram (Scott et al., 1967) and bull (Pursel \& Graham, 1967) despite the use of different extraction procedures, but is lower than the figures quoted for the boar (Johnson et al., 1969; Poulos et al., 1972). The extraction method of Bligh \& Dyer (1959) has not been generally used for the preparation of lipid extracts from spermatozoa or seminal plasma, but 
as far as spermatozoa are concerned, the method appears to give data comparable to the technique of Folch, Lees \& Sloane Stanley (1957) in at least three other species (Poulos et al., 1972).

The phospholipid composition of human spermatozoa appears to resemble that of the boar more closely (Johnson et al., 1969; Poulos et al., 1972) than that of the ram (Scott et al., 1967; Quinn \& White, 1967) or bull (Masaki \& Hartree, 1962; Pursel \& Graham, 1967). Choline plasmalogen comprises only $3 \%$ and $10 \%$ of human and boar sperm phospholipids, respectively, whereas it is by far the major component of ram and bull spermatozoa. Approximately $40 \%$ of the phospholipid of the latter two species are present as choline plasmalogen. On the other hand, human and boar spermatozoa contain considerably more sphingomyelin, phosphatidyl ethanolamine and ethanolamine plasmalogen than ram or bull spermatozoa.

When the percentage phospholipid composition of human seminal plasma is compared with the other three species, it is also apparent that its composition more closely resembles the boar than the other two species. Sphingomyelin is the predominant phospholipid type present in boar (Johnson et al., 1969) and human seminal plasma but in ram and bull seminal plasma (Quinn \& White, 1967; Pursel \& Graham, 1967), the choline phospholipids are the major fraction accounting for about half the total phospholipid. The latter phospholipid fraction comprises only about $10 \%$ of the phospholipids of human and boar seminal plasma. Phosphatidyl serine, present in only minor amounts in the spermatozoa of all species, and in ram and bull seminal plasma, constitutes about $12 \%$ of human and boar seminal plasma phospholipids.

The physiological significance of differences in phospholipid composition of spermatozoa are not understood. It was felt initially that differences in phospholipid composition might affect the structural characteristics of sperm membranes sufficiently to account for some properties, such as differences in the damage sustained on rapid cooling, i.e. cold shock. Although boar and human spermatozoa have similar phospholipid composition, however, there is a marked difference in their susceptibility to cold shock. Thus, human spermatozoa are fairly resistant to rapid cooling to $0^{\circ} \mathrm{C}$ (Wales \& White, 1959; White \& Wales, 1960), while boar spermatozoa are very sensitive to such changes (Lasley \& Bogart, 1944). Moreover, although the phospholipid composition of rabbit spermatozoa fairly closely resembles that of the boar (Poulos et al., 1972), rabbit spermatozoa are relatively resistant to cold shock (Wales \& White, 1959; White \& Wales, 1960). The total phospholipid composition of the various species, however, gives no indication of the lipid composition of the acrosome or of the outer sperm membranes, and since both of these organelles, and in particular the former, appear to be disrupted by coldshock in some species (Quinn, White \& Cleland, 1969; A. C. Darin, A. Poulos \& I. G. White, unpublished observations) an analysis of isolated acrosomal and outer membrane phospholipids may be required before any definite conclusion can be reached.

The absence of any significant degradation of human sperm phospholipids during prolonged incubation both in the presence and absence of either glucose or fructose, contrasted with similar experiments performed with washed ram 
spermatozoa (Hartree \& Mann, 1961) which showed a considerable hydrolysis of intracellular choline plasmalogen. These data would seem to indicate that the phospholipids of human spermatozoa, in contrast to ram spermatozoa, are not utilized as an energy source in the absence of oxidizable carbohydrates after ejaculation, at least in vitro.

\section{ACKNOWLEDGMENTS}

We are indebted to Professor C. W. Emmens for his interest and advice. The work has been aided by grants from the Australian Research Grants Committee and from the Ford Foundation. This investigation also received financial support from the World Health Organization. One of us (A.P.) was supported by a University of Sydney Post-Doctoral Fellowship.

\section{REFERENCES}

Anselt, G. B. \& Hawthorne, J. N. (1964) Phospholipids-metabolism and function, p. 42. Elsevier Publishing Co., London.

BLIGH, B. G. \& DYER, W. J. (1959) A rapid method of total lipid extraction and purification. Can. $\mathcal{F}$. Biochem. Physiol. 37, 911.

Dawson, R. M. C. (1960) A hydrolytic procedure for the identification and estimation of individual phospholipids in biological samples. Biochem. 7. 75, 45.

Dawson, R. M. G., Hemington, N. \& Davenport, J. B. (1962) Improvements in the method of determining individual phospholipids in complex mixtures by successive chemical hydrolysis. Biochem. F. 84, 497.

Dittmer, J. C. \& Wells, M. A. (1969) Quantitative and qualitative analysis of lipids and lipid components. Meth. Enzym. 14, 482.

Folch, J., Lees, M. \& Sloane Stanley, G. H. (1957) A simple method for the isolation and purification of total lipids from animal tissues. F. biol. Chem. 226, 497.

GotTfried, E. L. \& RAPPORT, M. M. (1962) Isolation and characterisation of phosphatidyl choline, a pure native plasmalogen. $\mathcal{F}$. biol. Chem. $237,329$.

Grogan, D. E., MAYER; D. T. \& SiKes, J. D. (1966) Quantitative differences in phospholipids of ejaculated spermatozoa and spermatozoa from three levels of the epididymis of the boar. $\mathcal{J}$. Reprod. Fert. 12, 431.

Hartree, E. F. \& ManN, T. (1961) Phospholipids in ram semen: metabolism of plasmalogen and fatty acids. Biochem. F. 80, 467.

Horrocks, L. A. (1968) The alk-l-enyl group content of mammalian myelin phosphoglycerides by quantitative 2-dimensional TLG. J. Lipid Res. 9, 469.

Johnson, L. A., Gerrits, R. J. \& Young, E. P. (1969) Quantitative analysis of porcine spermatozoa and seminal plasma phospholipids as affected by frequency of ejaculation. 7. Reprod. Fert. 19, 95.

Klotzsch, H. \& Bergmeyer, H. (1963) Methods of enzymatic analysis, p. 156. Academic Press, New York.

LASLEY, J. F. \& BOGART, R. (1944) A comparative study of epididymal and ejaculated spermatozoa of the boar. 7. Anim. Sci. 3, 360 .

MASAKI, J. \& HARTREE, E. F. (1962) Distribution of metabolic activity, phospholipid and hyaluronidase between heads and tails of bull spermatozoa. Biochem. 7. 84, 347 .

Minassian, E. S. \& Terner, C. (1966) Biosynthesis of lipids by human and fish spermatozoa. Am. $\mathcal{J}$. Physiol. 210, 615.

OwENs, K. (1966) A two-dimensional thin-layer chromatographic procedure for the estimation of plasmalogens. Biochem. 7. 100, 354.

Owens, K. \& Hughes, B. J. (1970) Lipids of dystrophic and normal mouse muscle; whole tissue and particulate fractions. 7 . Lipid Res. 11, 486.

Poulos, A., Darin, A. C. \& White, I. G. (1972) The phospholipids of mammalian spermatozoa. Proc. Aust. biochem. Soc. 5, 28.

Pursel, V. G. \& Graham, E. F. (1967) Phospholipids of bovine spermatozoa and seminal plasma. $\mathcal{F}$. Reprod. Fert. 14, 203.

Quins, P. J. \& WHITE, I. G. (1967) Phospholipid and cholesterol content of epididymal and ejaculated ram spermatozoa and seminal plasma in relation to cold shock. Aust. J. biol. Sci. 20, 1205. 
Quinn, P. J., White, I. G. \& Cleland, K. W. (1969) Chemical and ultrastructural changes in ram spermatozoa after washing, cold shock and freezing. F. Reprod. Fert. 18, 209.

Scott, T. W., Voglmayr, J. K. \& Setchell, B. P. (1967) Lipid composition and metabolism in testicular and ejaculated ram spermatozoa. Biochem. F. 102, 456.

Sweeley, C. C. \& Gaver, R. (1965) Methods of methanolysis of sphingolipids and direct determination of long chain bases by gas chromatography. 7. Am. Oil Chem. Soc. 42, 294.

Umbreit, W. W., Burris, R. H. \& Stauffer, J. F. (1959) Manometric techniques. Burgess Publishing Co., Minneapolis.

Wales, R. G. \& White, I. G. (1959) The susceptibility of spermatozoa to temperature shock. $\mathcal{F}$. Endocr. 19, 211.

White, I. G. \& Wales, R. G. (1960) The susceptibility of spermatozoa to cold shock. Int. F. Fert. 5, 195. 